\title{
Influence of barium borosilicate glass on microstructure and dielectric properties of $(\mathrm{Ba}, \mathrm{Ca})(\mathrm{Zr}, \mathrm{Ti}) \mathrm{O} 3$ ceramics
}

DOI:

10.1016/j.jeurceramsoc.2018.06.008

\section{Document Version}

Accepted author manuscript

Link to publication record in Manchester Research Explorer

\section{Citation for published version (APA):}

Khalf, A., \& Hall, D. (2018). Influence of barium borosilicate glass on microstructure and dielectric properties of (Ba,Ca)(Zr,Ti)O3 ceramics. Journal of the European Ceramic Society, 38(13).

https://doi.org/10.1016/j.jeurceramsoc.2018.06.008

\section{Published in:}

Journal of the European Ceramic Society

\section{Citing this paper}

Please note that where the full-text provided on Manchester Research Explorer is the Author Accepted Manuscript or Proof version this may differ from the final Published version. If citing, it is advised that you check and use the publisher's definitive version.

\section{General rights}

Copyright and moral rights for the publications made accessible in the Research Explorer are retained by the authors and/or other copyright owners and it is a condition of accessing publications that users recognise and abide by the legal requirements associated with these rights.

\section{Takedown policy}

If you believe that this document breaches copyright please refer to the University of Manchester's Takedown Procedures [http://man.ac.uk/04Y6Bo] or contact uml.scholarlycommunications@manchester.ac.uk providing relevant details, so we can investigate your claim.

\section{OPEN ACCESS}




\title{
Influence of barium borosilicate glass on microstructure and dielectric properties of $(\mathrm{Ba}, \mathrm{Ca})(\mathrm{Zr}, \mathrm{Ti}) \mathrm{O}_{3}$ ceramics
}

\author{
Abdulkarim Z. Khalf ${ }^{1,2 *}$ and David A. Hall ${ }^{2}$ \\ ${ }^{1}$ Applied Science Department, University of Technology, Baghdad, Iraq. \\ ${ }^{2}$ School of Materials, University of Manchester, Manchester M13 9PL, UK. \\ *Corresponding author: karim_out@yahoo.com
}

\begin{abstract}
Barium borosilicate (BBS) glass was added as a sintering aid to $\left(\mathrm{Ba}_{0.7} \mathrm{Ca}_{0.3}\right) \mathrm{TiO}_{3}-$ $\mathrm{Ba}\left(\mathrm{Ti}_{0.8} \mathrm{Zr}_{0.2}\right) \mathrm{O}_{3}$ (BCZT) ceramics at levels from 2 to $15 \mathrm{wt} \%$, yielding enhanced densification. The addition of BBS also induced changes in phase composition, from predominantly tetragonal to orthorhombic at room temperature. It is shown that the changes in phase content are caused by a shift of the orthorhombic to tetragonal phase transformation from below room temperature to $\approx 50{ }^{\circ} \mathrm{C}$. An additional high temperature transition around $120{ }^{\circ} \mathrm{C}$ was also identified. These observations are interpreted in terms of the development of chemical heterogeneity associated with the redistribution of dopant elements (particularly $\mathrm{Zr}$ and $\mathrm{Ca}$ ) through the liquid phase during sintering. The relative permittivity and electric field-induced polarisation values were generally degraded by the presence of the glass phase, but a reduction in ferroelectric hysteresis and improved densification behaviour have potential benefits in dielectric energy storage applications.
\end{abstract}

Keywords. X-ray diffraction, barium titanate, borosilicate, glass, dielectric. 


\section{Introduction}

Ferroelectric ceramic materials are used in a wide range of electrical devices as the basis for electromechanical actuators, sensors, transducers and high energy density capacitors. Ceramic capacitors have traditionally employed $\mathrm{BaTiO}_{3}$-based ceramics due to their high relative permittivity levels and the ability to tailor the temperature-dependence of dielectric properties to meet various industrial specifications $[1,2]$. On the other hand, recent attention has focused on $\left(\mathrm{Ba}_{0.7} \mathrm{Ca}_{0.3}\right) \mathrm{TiO}_{3}-\mathrm{Ba}\left(\mathrm{Zr}_{0.2} \mathrm{Ti}_{0.8}\right) \mathrm{O}_{3}$ (BCZT) solid solutions as potential lead-free piezoceramic materials due to their promising piezoelectric properties (e.g. $d_{33}>600 \mathrm{pC} / \mathrm{N}$ ), albeit with a low ferroelectric Curie temperature, $T_{\mathrm{C}} \approx 90^{\circ} \mathrm{C}[3-7]$.

Liu and Ren investigated the phase boundaries within the pseudo-binary BCT-BZT solid solution using a combination of temperature-dependent XRD and dielectric measurements; it was reported that the phase diagram is characterised by an MPB between ferroelectric rhombohedral (BZT-rich) and tetragonal (BCT-rich) phases [8]. In addition, a CubicRhombohedral-Tetragonal (C-R-T) triple point was identified for a composition with $\mathrm{x}=0.32$ at $57^{\circ} \mathrm{C}$. The phase diagram was subsequently refined by Keeble et al. [9], who identified an intermediate orthorhombic (O) phase for compositions near to $\mathrm{x}=0.5$ using high resolution synchrotron $\mathrm{x}$-ray powder diffraction (SXPD).

The high calcination $\left(\approx 1350{ }^{\circ} \mathrm{C}\right)$ and sintering $\left(\approx 1500{ }^{\circ} \mathrm{C}\right)$ temperatures needed for processing BCZT ceramics can lead to practical difficulties for some applications $[4,10,11]$. Therefore, several approaches have been investigated in order to synthesise such materials at lower sintering temperatures; these have included the addition of sintering aids $[12,13]$, low melting point oxides [14] and doping of other cations in solid solution [15]. In addition, the use of lower sintering temperatures for BCZT is one of the requirements to make thick films. Bai et al. [16] prepared a fully dense, textured BCZT piezoelectric thick film using a screen printing method, which demonstrated significant improvements in electric fieldinduced polarisation and strain as a result of preferred grain orientation. However, the films were deposited on platinum substrates and a temperature of $1300{ }^{\circ} \mathrm{C}$ was required for sintering.

Glass additives have been identified previously as a potential means to reduce the sintering temperature of BCZT. The fabrication of glass-modified BCZT ceramics was reported by Puli et al. [17], who studied the effect of $\mathrm{BaO}-\mathrm{B}_{2} \mathrm{O}_{3}-\mathrm{ZnO}$ on the dielectric properties of $\mathrm{BCZT}$ with a view to their use as energy storage dielectrics. The resulting samples were composites comprising a mixture of BCZT and glass, yielding dielectric breakdown field strengths of 
$\approx 28 \mathrm{kV} \mathrm{mm}^{-1}$ with recoverable energy density values of approximately $0.50 \mathrm{~J} \mathrm{~cm}^{-3}$. The effect of up to $9 \mathrm{wt} \%$ of $\mathrm{CaO}-\mathrm{B}_{2} \mathrm{O}_{3}-\mathrm{SiO}_{2}$ (CBS) glass additions on the microstructure and electrical properties of BCZT was also studied by Lai et al [18]. The coexistence of orthorhombic and tetragonal $\mathrm{BCZT}$ phases with a small amount of $\mathrm{CaTiO}_{3}$ secondary phase was observed using XRD. Most of these investigations demonstrate that lower sintering temperatures for BCZT ceramics can be achieved by the use of suitable sintering aids. However, the sintering temperatures employed tend to be in the range higher than $1300{ }^{\circ} \mathrm{C}$ $[12,15,19]$.

The ternary system $\mathrm{BaO}-\mathrm{B}_{2} \mathrm{O}_{3}-\mathrm{SiO}_{2}$ (BBS) exhibits a eutectic reaction at a temperature of $1140{ }^{\circ} \mathrm{C}$ for the composition $0.55-0.19-0.26$; this specific composition was identified by Shukla on the basis of its low ternary eutectic melting point [20]. On cooling such a liquid, crystallisation is generally avoided and an amorphous glassy phase is formed. BBS glasses exhibit high hardness, low thermal expansion coefficient, low dielectric loss and low cost, which means that they are well suited to applications in Low Temperature Co-fired Ceramic (LTCC) technology $[21,22]$.

The aim of the present work was to evaluate the performance of BBS as a sintering aid in BCZT ceramics. The BBS glass was added to the calcined BCZT powder in varying proportions according to the formula (1-x)BCZT-xBBS, with $x=2,5,10$ and 15 wt\%, using sintering temperatures in the range from 1100 to $1300{ }^{\circ} \mathrm{C}$. The influence of $\mathrm{BBS}$ on densification, phase coexistence, microstructure and dielectric/ferroelectric properties of BCZT were investigated.

\section{Experimental procedures}

$\mathrm{Ba}_{0.85} \mathrm{Ca}_{0.15} \mathrm{Ti}_{0.9} \mathrm{Zr}_{0.1} \mathrm{O}_{3}$ powder, corresponding to the 50-50 BCT-BZT composition, was synthesized by solid state reaction. The precursor materials were $\mathrm{BaCO}_{3}(99 \%), \mathrm{CaCO}_{3}$ (98\%), $\mathrm{ZrO}_{2}(99 \%)$ and $\mathrm{TiO}_{2}$ (99\%). These powders were weighed out and mixed by ball milling in propan-2-ol with zirconia milling media for 24 hours. The mixed oxides were dried and then calcined at a temperature of $1000{ }^{\circ} \mathrm{C}$ for 6 hours.

The BBS glass system was prepared according to the composition $0.546 \mathrm{BaO}-0.195 \mathrm{~B}_{2} \mathrm{O}_{3}-$ $0.259 \mathrm{SiO}_{2}$ using $\mathrm{BaCO}_{3}(99 \%), \mathrm{H}_{3} \mathrm{BO}_{3}(99.5 \%)$ and $\mathrm{SiO}_{2}(99.5 \%)$ as raw materials. The precursors were mixed and milled using the same procedures employed for the BCZT powder. Then, the mixed oxide powders were dried and melted at a temperature of $1140{ }^{\circ} \mathrm{C}$ for $60 \mathrm{~min}$ in an alumina crucible and quenched in air onto a stainless steel plate having a thickness of $2 \mathrm{~mm}$. 
BCZT was mixed with BBS glass as a sintering aid according to the composition (1-x)BCZT$x B B S$, with $x=2,5,10$ and $15 w t \%$. Here, the BCZT calcined powder and BBS glass powder were mixed and milled for 6 hours in propan-2-ol in a similar way to that described in the preparation of the BCZT powder above. After drying for 24 hours, the mixture was pressed into disks of diameter $10 \mathrm{~mm}$ and thickness $2 \mathrm{~mm}$ by applying a pressure of $100 \mathrm{MPa}$ in a cylindrical steel die. The green pellets were sintered at temperatures of 1100, 1200 and $1300{ }^{\circ} \mathrm{C}$ for 3 hours. In addition, pure BCZT ceramics were prepared by compaction at 100 MPa and subsequent sintering at temperatures up to $1400^{\circ} \mathrm{C}$. The bulk densities for all of the sintered ceramic pellets were determined using the geometric method.

The phase composition of the sintered ceramics was analysed using high resolution SXPD on beamline I11 at the Diamond Light Source, UK, using a wavelength of $0.8259 \AA$. The crushed ceramic powders were loaded into quartz capillaries of $0.5 \mathrm{~mm}$ diameter, and then mounted on the beamline using a spinning brass holder. The Cryostar hot air blower was used to heat the sample from 30 to $150{ }^{\circ} \mathrm{C}$, with a heating rate of $5^{\circ} \mathrm{C} \mathrm{min}^{-1}$. Diffraction patterns were recorded using the position sensitive detector (PSD), which was calibrated using a lanthanum hexaboride powder standard. Full-pattern fitting was carried out using Topas v5.0 $[23,24]$.

Polished sections for microscopic observations were prepared by grinding using 400 to 2400 grade SiC and then polishing using 6,1 , and $1 / 4$ micron diamond paste, followed by dilute OPS (Oxide Polishing Suspension) colloidal silica solution for $\approx 90$ minutes. Finally, the samples were placed in an ultrasonic bath for cleaning under ethanol for $10 \mathrm{~min}$. A thin conductive carbon coating was applied using a Quorum coater (Q150T). The microstructural examination was carried out using a Quanta FEG 650 SEM, with local chemical information being obtained by EDS analysis. During the experiment, the accelerating voltage was $20 \mathrm{kV}$ and the working distance was approximately $10 \mathrm{~mm}$. For microstructural analysis, the linear intercept method was used in order to determine the grain size of the sintered ceramics [25].

Electrodes were applied to the sintered pellets using a silver paint (C2000107P3, Gwent Electronic Materials, UK), fired-on at a temperature of $550{ }^{\circ} \mathrm{C}$ for $30 \mathrm{~min}$. The relative permittivity and loss tangent were measured as a function of temperature at frequencies of 1, 10 and $100 \mathrm{kHz}$ using a Hewlett-Packard HP4284A LCR meter. High field ferroelectric polarisation-electric field (P-E) measurements were conducted at a frequency of $2 \mathrm{~Hz}$ under silicone oil over a range of temperatures from 20 to $140{ }^{\circ} \mathrm{C}$ using a Hewlett-Packard HP33120A function generator in conjunction with an EHT Amplifier (Chevin Research Ltd, 
Otley, UK) and a current amplifier [26]. Simultaneous strain-electric field and polarisationelectric field measurements were also conducted at $20{ }^{\circ} \mathrm{C}$ using an AixACCT TF 2000 Ferroelectric Analyzer, with a measurement frequency of $1 \mathrm{~Hz}$.

\section{Results and discussion}

\subsection{Relative density analysis}

The relative densities of the pure BCZT ceramics sintered at 1300,1350 and $1400{ }^{\circ} \mathrm{C}$ were determined as 81,84 and $91 \%$ respectively, confirming that high sintering temperatures are necessary to achieve significant densification of BCZT in the absence of sintering aids.

Figure 1(a) illustrates the variation in theoretical density of the BCZT-BBS ceramic-glass composite as a function of the BBS content. In order to obtain this figure, the theoretical density of the pure crystalline BCZT phase was calculated first using the nominal composition together with the phase fractions and crystallographic parameters, determined from the full-pattern XRD analysis described in section3.2 below, while the density of the glass phase was measured by immersion in water using the Archimedes method. Subsequently, the theoretical density of the ceramic-glass composite, $\rho_{\mathrm{t}}$, was calculated according to the following mixing equation.

$$
\frac{1}{\rho_{\mathrm{t}}}=\frac{1-\mathrm{x}}{\rho_{1}}+\frac{\mathrm{x}}{\rho_{2}}
$$

where $\rho_{1}$ and $\rho_{2}$ are the density of the ceramic and glass phases respectively and $x$ is the glass content in wt\%.

It was found that the theoretical density of the ceramic-glass composite decreases with glass content, as illustrated in Figure 1(a). This effect can be attributed to the lower density of the glass phase in comparison with $\mathrm{BCZT}$; these were determined as $\approx 4.1$ and $5.7 \mathrm{~g} \mathrm{~cm}^{-3}$ respectively.

The relative densities of the BCZT-BBS ceramics sintered at a temperature of $1100{ }^{\circ} \mathrm{C}$, shown in Figure $1(\mathrm{~b})$, were all in the region of $85 \%$ or less, indicating poor densification at such low temperatures. Increasing the sintering temperature to $1200{ }^{\circ} \mathrm{C}$ resulted in an increase in relative density to values in the range 91 to $94 \%$, which suggests that the BBS liquid phase can be considered as an effective sintering aid for BCZT. However, reductions in density were observed at the higher sintering temperature of $1300{ }^{\circ} \mathrm{C}$. The latter effect could be due to volatilisation of $\mathrm{B}_{2} \mathrm{O}_{3}$ at high temperatures, as reported by Lai [18]. 
For temperatures of $1200{ }^{\circ} \mathrm{C}$ and above, the relative density values were moderately independent of BBS content up to approximately 10 wt\% BBS. However, significant reductions in density were observed for BBS contents beyond this level. Microstructural observations, described in section 0 below, indicate that the increased porosity in BCZT ceramics prepared with high BBS contents is predominantly in the form of large $(\approx 10 \mu \mathrm{m})$ pores associated with compaction defects. The use of improved processing procedures (e.g. employing lubricants or cold isostatic pressing) could help to prevent the formation of such defects and hence yield further improvements in densification.
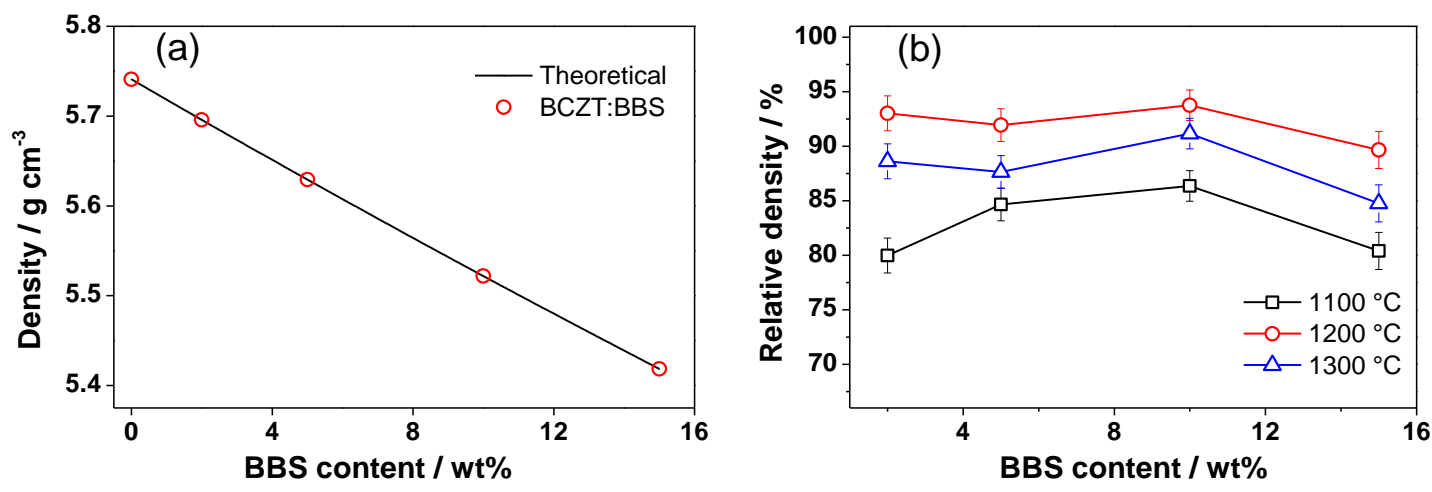

Figure 1. Influence of BBS content on (a) theoretical density and (b) relative density of BCZT-BBS ceramics sintered at temperatures ranging from 1100 to $1300^{\circ} \mathrm{C}$.

\subsection{Structural studies at room temperature}

SXPD patterns of the sintered pure BCZT ceramics are presented in Figure 2 (a). These patterns are consistent with a perovskite phase, with no evidence to indicate the presence of any other crystalline second phases. Asymmetry and/or peak splitting in both of the pseudo-cubic $\{111\}_{p}$ and $\{200\}_{p}$ peak profiles suggests the presence of at least 2 different types of structurally-distorted perovskite phases; this observation is consistent with previous reports, which indicate that BCZT ceramics having the present composition are likely to contain coexisting orthorhombic $(\mathrm{O})$ and tetragonal $(\mathrm{T})$ phases at room temperature [9]. The individual peak profiles were generally narrower at the higher sintering temperatures, indicating an improved crystallinity associated with the larger grain sizes.

The incorporation of BBS into BCZT ceramics had relatively little impact on the overall appearance of the SXPD patterns, as shown in Figure 2 (b). The presence of the glass phase did not appear to cause any significant reactions with BCZT or lead to additional crystalline second phases. However, subtle changes in the individual peak profiles are apparent, which could indicate variations in the phase fractions of the coexisting perovskite-type phases. $A$ general narrowing of the peak profiles of the BCZT-BBS ceramics sintered at $1200{ }^{\circ} \mathrm{C}$, in 
comparison with those of pure BCZT sintered at 1300 and $1350{ }^{\circ} \mathrm{C}$, was attributed to improved crystallinity; this observation suggests that the presence of the glass phase facilitates grain growth during sintering.
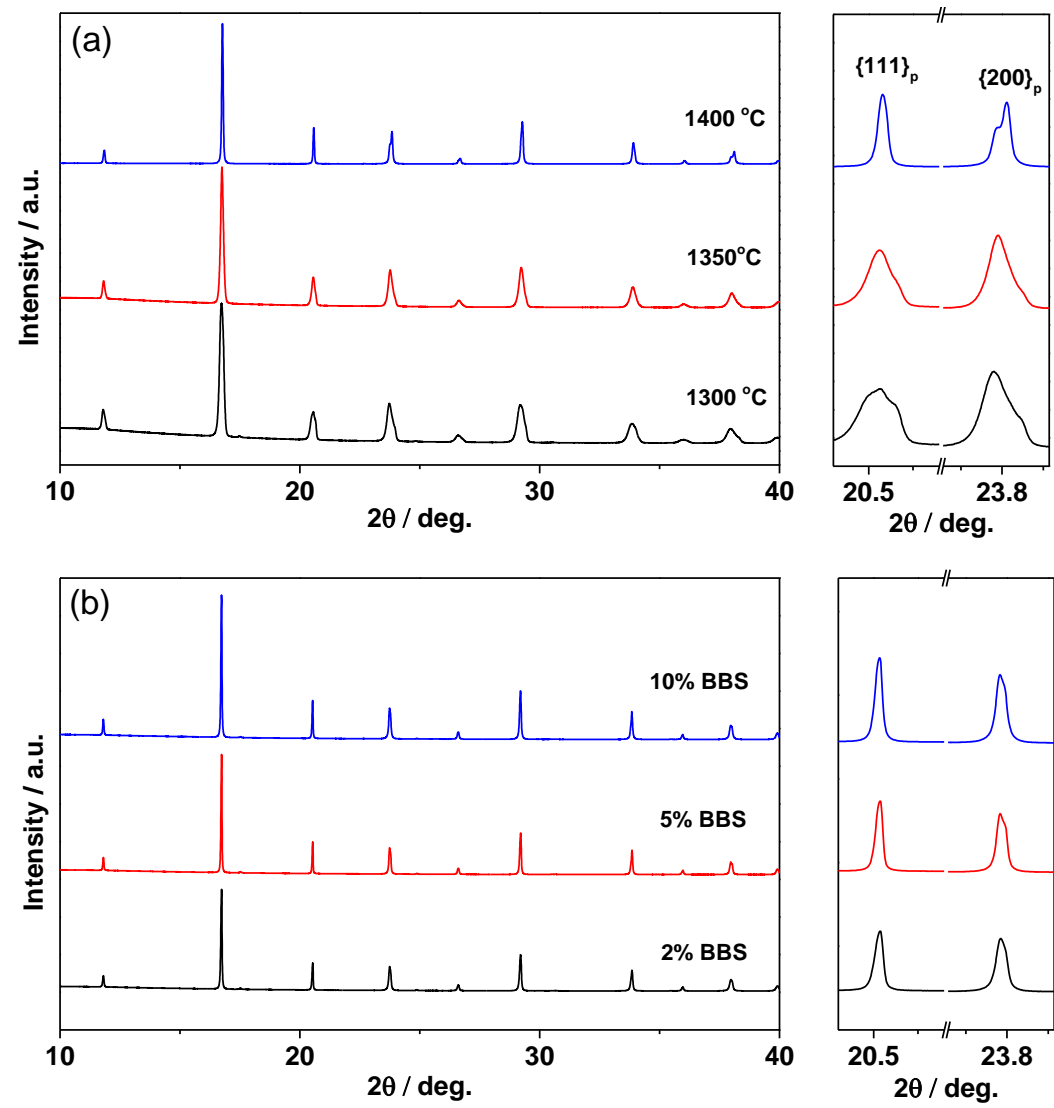

Figure 2. SXPD patterns of (a) pure BCZT ceramics sintered at temperatures from 1300 to $1400{ }^{\circ} \mathrm{C}$ (b) BCZT-BBS ceramics with various BBS contents sintered at $1200^{\circ} \mathrm{C}$.

The results of full-pattern fitting, shown in Figure 3 and

Table 1 , indicate that the pure BCZT ceramic sintered at $1400{ }^{\circ} \mathrm{C}$ comprised coexisting orthorhombic $(\mathrm{O})$ and tetragonal $(\mathrm{T})$ phases with $\mathrm{O}$ and $\mathrm{T}$ phase fractions of approximately 19 and $81 \%$ respectively. The addition of $5 \mathrm{wt} \%$ BBS glass favoured the formation of the orthorhombic (O) and rhombohedral (R) phases, yielding phase fractions of $78 \%$ and $22 \%$ for the coexisting $\mathrm{O}$ and $\mathrm{R}$ phases respectively. The increase in the proportion of $\mathrm{O}$ phase and appearance of the R phase with increasing BBS content is consistent with an increase in the O-T phase transformation temperature, $\mathrm{T}_{\mathrm{O}-\mathrm{T}}$, as described below in section 3.4 , since this acts to stabilise the orthorhombic phase at room temperature. Furthermore, the glassmodified BCZT ceramics prepared with a variety of glass contents yielded similar results for the coexisting $\mathrm{O}$ and $\mathrm{R}$ phases, albeit with slightly different phase fractions, as shown in Table 1. 

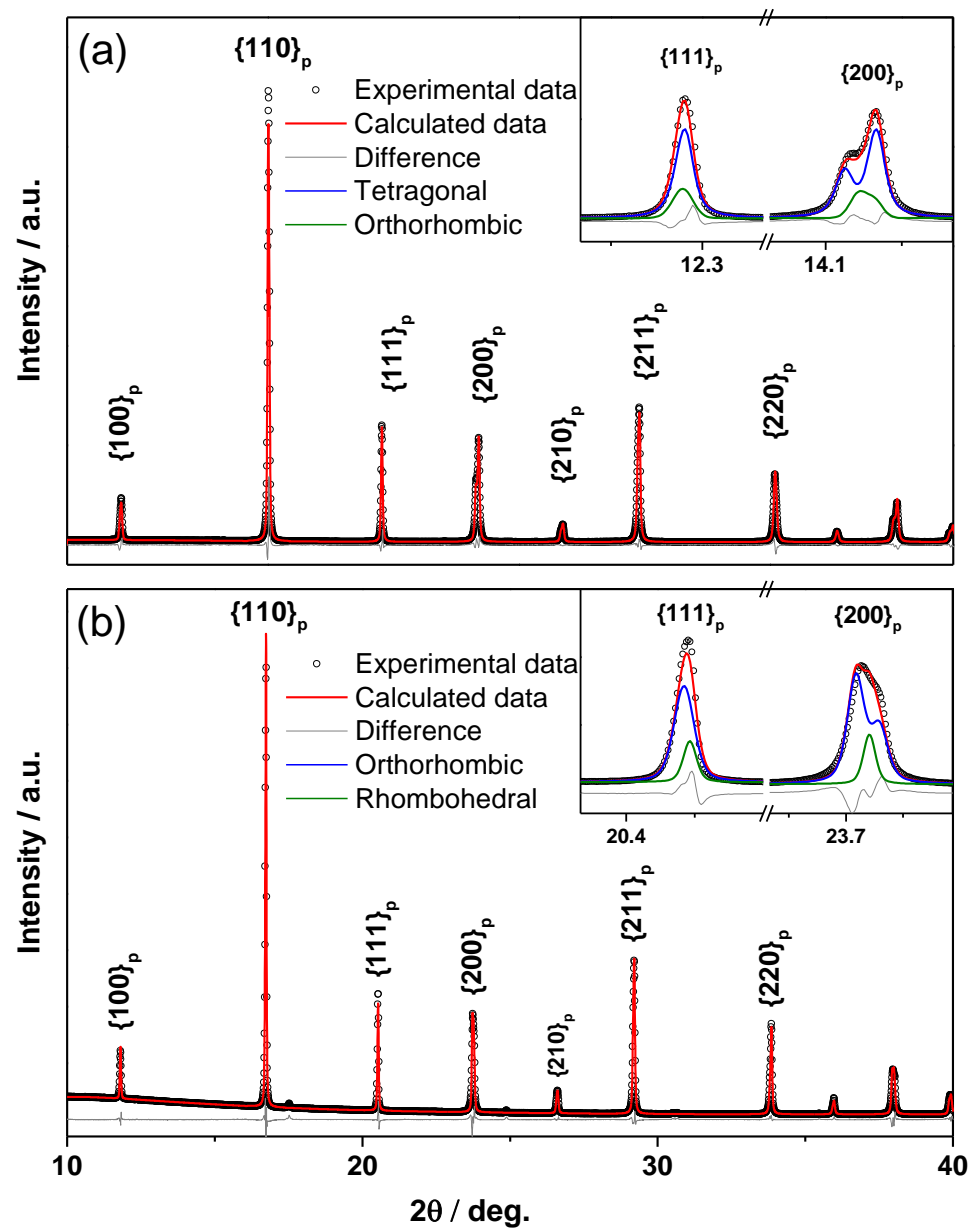

Figure 3. Comparison of experimental and calculated SXPD peak profiles of (a) pure BCZT ceramic sintered at $1400^{\circ} \mathrm{C}$ and (b) BCZT-5 wt\% BBS ceramic sintered at $1200{ }^{\circ} \mathrm{C}$.

Table 1. Coexisting phases, phase fractions, lattice parameters, $\chi^{2}$ and $R_{w p}$ of BCZT ceramics.

Numbers in parentheses are statistical standard deviations of the last significant digit.

\begin{tabular}{|c|c|c|c|c|c|c|c|}
\hline \multirow{2}{*}{$\begin{array}{l}\text { Composition } \\
\text { (sintering } \mathrm{T} \text { ) }\end{array}$} & \multirow{2}{*}{$\begin{array}{l}\text { Phase fraction } \\
\text { / wt } \%\end{array}$} & \multicolumn{4}{|c|}{ Lattice parameter } & \multirow{2}{*}{$x^{2}$} & \multirow{2}{*}{$\mathrm{R}_{\mathrm{wp}}$} \\
\hline & & a / $\AA$ & $\mathrm{b} / \AA$ & $c / \AA$ & $\alpha /{ }^{\circ}$ & & \\
\hline \multirow{2}{*}{$\begin{array}{l}\text { Pure BCZT } \\
\left(1400^{\circ} \mathrm{C}\right)\end{array}$} & $\mathrm{T}=81(2)$ & $a_{T}=3.9963(3)$ & -- & $c_{T}=4.0139(2)$ & -- & \multirow{2}{*}{6.1} & \multirow{2}{*}{6.77} \\
\hline & $\mathrm{O}=19(1)$ & $a_{0}=5.6642(2)$ & $b_{0}=3.9972(3)$ & $c_{0}=5.6673(3)$ & -- & & \\
\hline $\begin{array}{l}\text { BCZT-2BBS } \\
\left(1200^{\circ} \mathrm{C}\right)\end{array}$ & $\begin{array}{l}O=75(2) \\
R=25(1)\end{array}$ & $\begin{array}{l}a_{0}=5.6775(1) \\
a_{p}=4.0089(1)\end{array}$ & $\mathrm{b}_{0}=4.0032(2)$ & $\begin{array}{l}c_{0}=5.6785(3) \\
--\end{array}$ & $\begin{array}{l}-- \\
89.96(1)\end{array}$ & 5.19 & 4.23 \\
\hline \multirow{2}{*}{$\begin{array}{l}\text { BCZT-5BBS } \\
\left(1200^{\circ} \mathrm{C}\right)\end{array}$} & $0=78(3)$ & $a_{0}=5.6771(5)$ & $b_{0}=4.0057(1)$ & $c_{0}=5.6819(4)$ & $89.98(1)$ & \multirow{2}{*}{5.6} & \multirow{2}{*}{4.55} \\
\hline & $\mathrm{R}=22(1)$ & $a_{R}=4.0101(3)$ & -- & -- & & & \\
\hline \multirow{2}{*}{$\begin{array}{l}\text { BCZT-10BBS } \\
\left(1200^{\circ} \mathrm{C}\right)\end{array}$} & $\mathrm{O}=82(1)$ & $a_{0}=5.6789(1)$ & $b_{0}=4.0052(2)$ & $c_{0}=5.6790(3)$ & -- & \multirow{2}{*}{6.29} & \multirow{2}{*}{4.76} \\
\hline & $=18(2)$ & $a_{R}=4.0103(4)$ & -- & -- & $89.97(1)$ & & \\
\hline
\end{tabular}




\subsection{Microstructure}

The SEM micrographs of the pure and BBS-modified BCZT ceramics are shown in Figure 4. Poor densification and a very fine grain size are apparent for the pure BCZT ceramic sintered at $1300{ }^{\circ} \mathrm{C}$, consistent with the low relative density of $81 \%$ reported in section 3.1 above. Increasing the sintering temperature for pure BCZT led to a reduction of porosity and enhanced grain growth, yielding an average grain size of $12.2 \pm 4.1 \mu \mathrm{m}$ for a sintering temperature of $1400{ }^{\circ} \mathrm{C}$. In contrast, significant reductions in porosity and limited grain growth are already apparent at the lower sintering temperature of $1200{ }^{\circ} \mathrm{C}$ for the BBSmodified BCZT ceramics.

At a given sintering temperature, the effect of adding BBS was to enhance densification and grain growth. On the other hand, the ultimate grain sizes of the BCZT-BBS ceramics were somewhat lower than those of pure BCZT due to the different ranges of sintering temperatures employed in the present study. For example, the average grain size for the BCZT-10 wt\% BBS ceramic, sintered at $1200{ }^{\circ} \mathrm{C}$ was $2.9 \pm 0.2 \mu \mathrm{m}$, significantly smaller than that of pure $\mathrm{BCZT}$ sintered at $1400{ }^{\circ} \mathrm{C}$. The presence of the glassy phase between the grains became more clearly apparent with increasing BBS content and sintering temperature, as illustrated in Figure 5.

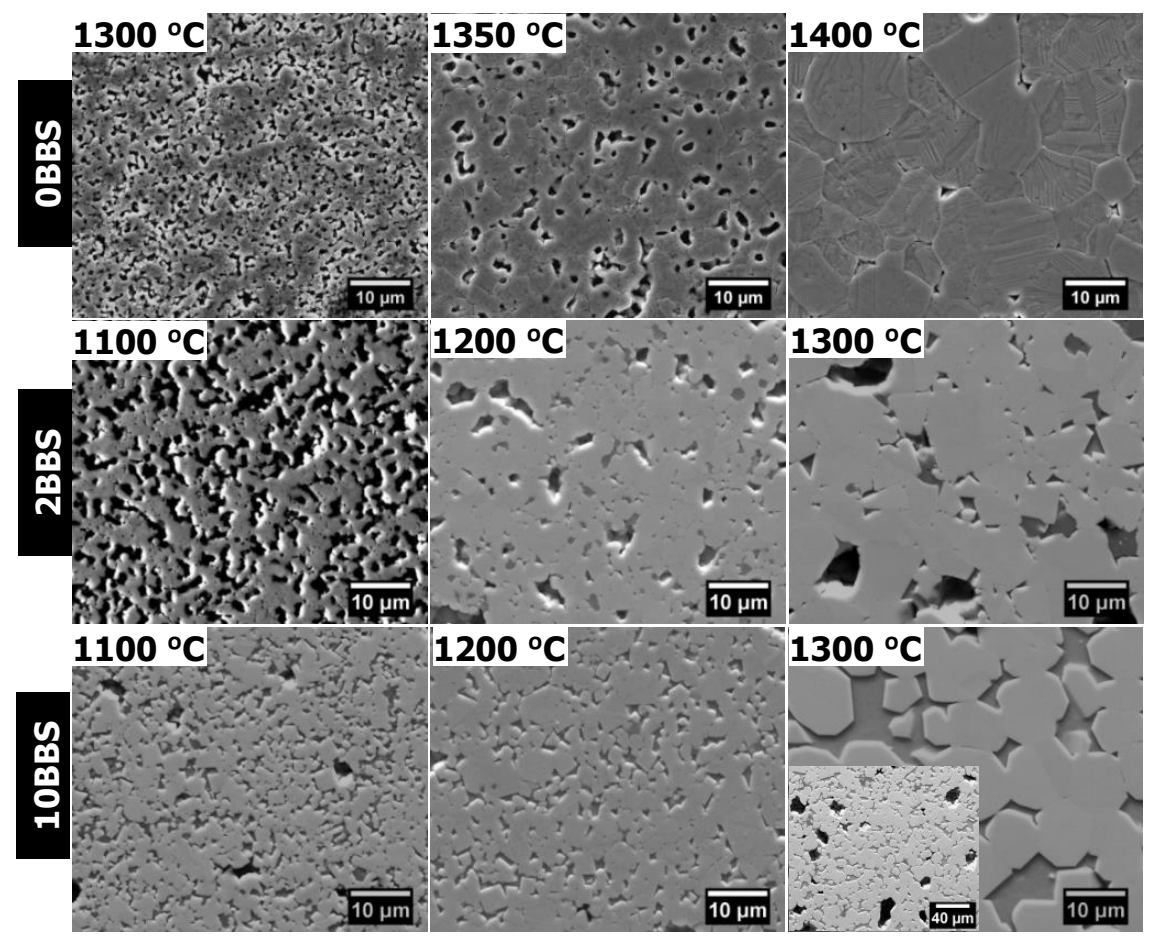

Figure 4. SEM micrographs of BCZT-BBS ceramics with 0,2 and 10 wt\% BBS sintered at temperatures in the range $1100^{\circ} \mathrm{C}$ to $1400^{\circ} \mathrm{C}$, imaged using SE mode. 
Although densification was much improved in the glass-modified BCZT ceramics, some isolated large pores were present, giving rise to slight reductions in density at high glass contents, as noted in section 3.1 above. The size and morphology of these pores, presented as the insert in Figure $4\left(10 \mathrm{BBS} / 1300{ }^{\circ} \mathrm{C}\right)$, suggests that they may originate from the inhomogeneous distribution of the glass phase in the powder and/or compaction defects. EDS mapping was employed to determine the distribution of BCZT and BBS phases in the BCZT-10BBS ceramic, as illustrated by the results shown in Figure 5. It is evident that the heavier metallic elements, represented by $\mathrm{Ba}$ and $\mathrm{Ti}$, are distributed uniformly throughout the crystalline BCZT grains while the lighter elements, represented by $\mathrm{Si}$, are concentrated in the glassy BBS phase, which occurs as a continuously connected matrix between the grains.

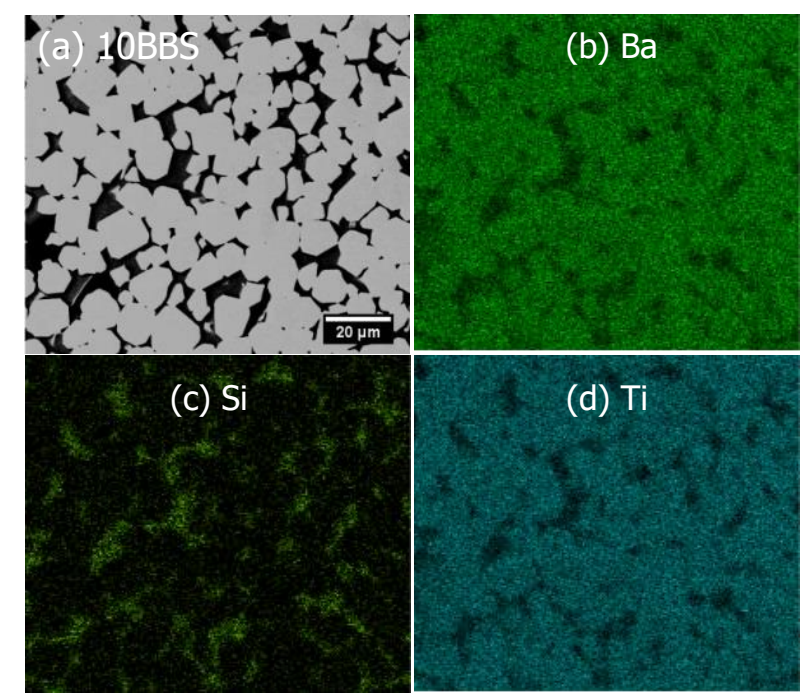

Figure 5. (a) BSE micrograph of the polished section and (b) to (d) EDS mapping for BCZT-10BBS ceramic sintered at $1300^{\circ} \mathrm{C}$.

\subsection{Dielectric properties}

The temperature-dependence of relative permittivity and loss for pure BCZT ceramics is shown in Figure 6 . In the case of the ceramic sintered at $1400{ }^{\circ} \mathrm{C}$, a high relative permittivity in the region of 3800 was obtained at room temperature, consistent with previous reports [27]. Furthermore, a relatively sharp peak was apparent at a temperature of $82{ }^{\circ} \mathrm{C}$. On the basis of previous results, it is assumed that this peak is associated with the ferroelectric Curie point, $T_{c}$, and corresponds to the structural transformation from tetragonal $(T)$ to cubic $(C)$. Although the $\varepsilon_{r}-T$ curve does not exhibit any obvious anomalies in the region below $T_{C}$, small variations in tan $\delta$ in the temperature range from 30 to $40{ }^{\circ} \mathrm{C}$ could be associated with the onset of the lower-temperature $\mathrm{O}$ to $\mathrm{T}$ transition and therefore may account for the minor orthorhombic phase fraction identified by SXPD, as reported above. 
In contrast, the relative permittivity values for the pure BCZT ceramics sintered at 1300 and $1350{ }^{\circ} \mathrm{C}$ were significantly lower and did not show such a strong peak at the Curie point. These changes in the $\varepsilon_{r}-T$ relationships are attributed to the combination of low density/high porosity and poor crystallinity of these materials.
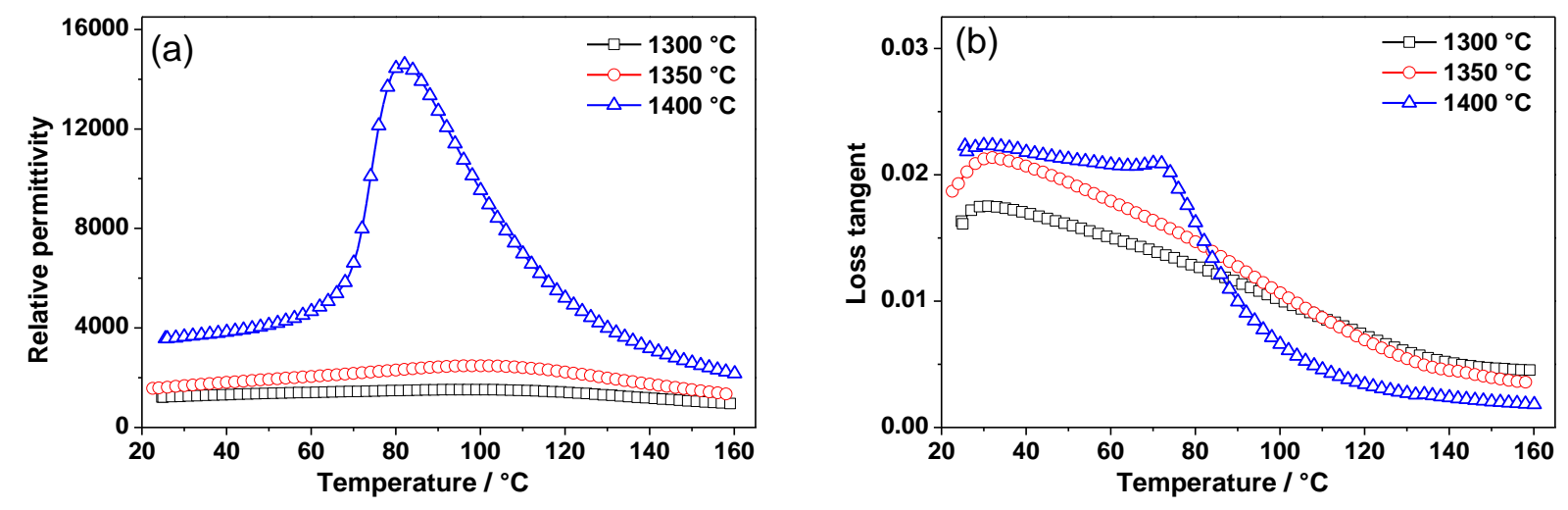

Figure 6. Influence of sintering temperature on (a) relative permittivity and (b) loss tangent for pure $\mathrm{BCZT}$, measured at a frequency of $100 \mathrm{kHz}$.

The influence of BBS glass on the dielectric properties of BCZT ceramics is illustrated by the results presented in Figure 7. In common with the case for pure BCZT, the use of higher sintering temperatures yields improved densification and crystallinity, leading to higher relative permittivity values and a more clearly-defined peak at the Curie temperature, as shown in Figure 7 (a) for BCZT-5BBS.

An additional shoulder around $50{ }^{\circ} \mathrm{C}$ is clearly apparent on the $\varepsilon_{r}-\mathrm{T}$ curves for the materials sintered at temperatures above $1200{ }^{\circ} \mathrm{C}$, which is attributed to the thermally-induced $\mathrm{O}-\mathrm{T}$ transformation. Therefore, it is apparent that the O-T transformation temperature increased from below room temperature to approximately $50^{\circ} \mathrm{C}$ as a result of the BBS glass addition. These results are in agreement with the analysis of the SXPD patterns in section 3.2 above, which indicated that the addition of the BBS glass phase led to a change from predominantly tetragonal to orthorhombic phases at room temperature. Furthermore, a similar increase in the $\mathrm{R}-\mathrm{O}$ transformation temperature could be responsible for the coexisting minor R-phase that was identified by analysis of the SXPD patterns.

For a sintering temperature of $1300{ }^{\circ} \mathrm{C}$, the addition of BBS to BCZT ceramics led to a general reduction in permittivity values as a result of the low permittivity of the BBS glass phase $\left(\varepsilon_{\mathrm{r}} \approx 10.5\right)$, which acts as a screening layer between the higher permittivity BCZT grains. BCZT-BBS ceramics prepared with various BBS contents all exhibited a clear shoulder in their $\varepsilon_{r}$-T curves at temperatures ranging from 40 to $60{ }^{\circ} \mathrm{C}$, as shown in Figure 7 (c). 
Furthermore, there was a slight reduction in the position of the main peak at the Curie point and an increase in that of the lower-temperature shoulder with increasing glass content.

The appearance of the O-T transformation in the region above room temperature indicates that the presence of the glass leads to subtle changes in the chemical composition of the crystalline perovskite phase. According to the phase diagram of the BCT-BZT system, even a slight change of the BCT/BZT ratio can lead to significant modification of the phase transformation temperatures $[9,28]$. More specifically, reduction of the $\mathrm{Ca} / \mathrm{Zr}$ ratio in the perovskite phase could be the origin of the observed increase in $\mathrm{T}_{\mathrm{O}-\mathrm{T}}$, from below room temperature to $\approx 50{ }^{\circ} \mathrm{C}$. One possible mechanism to achieve this could be the selective dissolution of $\mathrm{CaTiO}_{3}$ into the liquid phase during sintering.

The absence of crystalline second phases in the sintered glass-modified BCZT ceramics suggests that the small amount of additional $\mathrm{CaTiO}_{3}$ could be incorporated within the glass phase during cooling. This proposal is reasonable given that $\mathrm{CaO}$ and $\mathrm{TiO}_{2}$ are well-known as modifiers for silicate glasses $[29,30]$. These observations support the view that the chemical composition of the perovskite phase is significantly affected by the presence of the BBS liquid phase during sintering, resulting in a reduction of the $\mathrm{Ca} / \mathrm{Zr}$ ratio.

An additional inflection is evident in the $\varepsilon_{r}-\mathrm{T}$ curves for BCZT-10BBS and BCZT-15BBS at a temperature of approximately $120{ }^{\circ} \mathrm{C}$. Although the origin of this anomaly cannot be decisively identified at present, it could also be caused by chemical heterogeneity. For example, the dissolution of both $\mathrm{Ca}$ and $\mathrm{Zr}$ from some perovskite BCZT grains could lead to the formation of pure $\mathrm{BaTiO}_{3}$ grains, which would exhibit a higher Curie temperature, in the range 120 to $130{ }^{\circ} \mathrm{C}$ [31]. Therefore, the occurrence of chemical heterogeneity, resulting from the dissolution of dopants into the liquid phase can in principle explain the observed changes in both $T_{C}$ and $T_{\text {O-T }}[1,32]$. Further evidence, in the form of more precise microchemical analysis, would help to support this argument. 

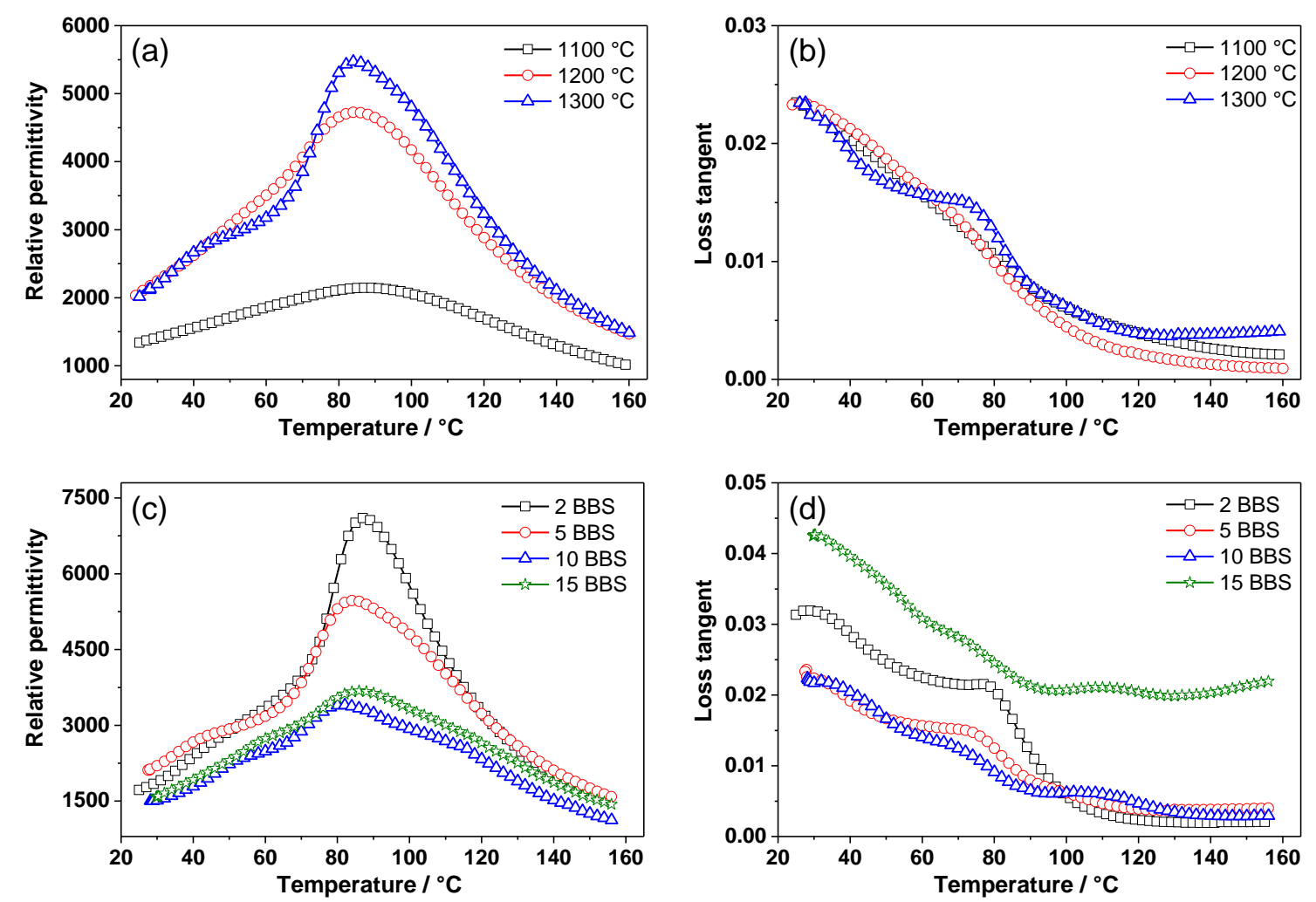

Figure 7. Temperature-dependence of relative permittivity and loss tangent for (a)-(b) BCZT-5BBS sintered at $1100{ }^{\circ} \mathrm{C}$ to $1300^{\circ} \mathrm{C}$ and (c)-(d) BCZT-BBS sintered at $1300^{\circ} \mathrm{C}$.

\subsection{Thermally-induced phase transformations}

From the BCT-BZT phase diagram [11], it can be seen that the tilt in the MPB of the BCZT system leads to the possibility to approach the MPB by changing temperature as well as the composition. Therefore, the use of in-situ SXPD during heating provides the means to identify the phase changes that occur on approaching or crossing the MPB.

The temperature-dependent in-situ SXPD patterns for BCZT-5BBS sintered at $1200{ }^{\circ} \mathrm{C}$ are shown in Figure 8, which presents the changes in the $\{200\}_{p}$ peak profile on heating from 30 to $150^{\circ} \mathrm{C}$. It is expected that a chemically-homogeneous BCZT ceramic should transform to a cubic structure at temperatures above the Curie point. In the present case, the transition to the cubic phase occurred above the Curie temperature of $\approx 85^{\circ} \mathrm{C}$. Furthermore, significant changes in the peak profiles are evident in the intermediate temperature range. These results are generally in agreement with the dielectric property measurements, shown in Figure 7Error! Reference source not found. above, where the two transition temperatures, corresponding to the $\mathrm{O}-\mathrm{T}$ and $\mathrm{T}-\mathrm{C}$ transformations of BCZT5BBS, were determined as approximately 50 and $85^{\circ} \mathrm{C}$ respectively. 

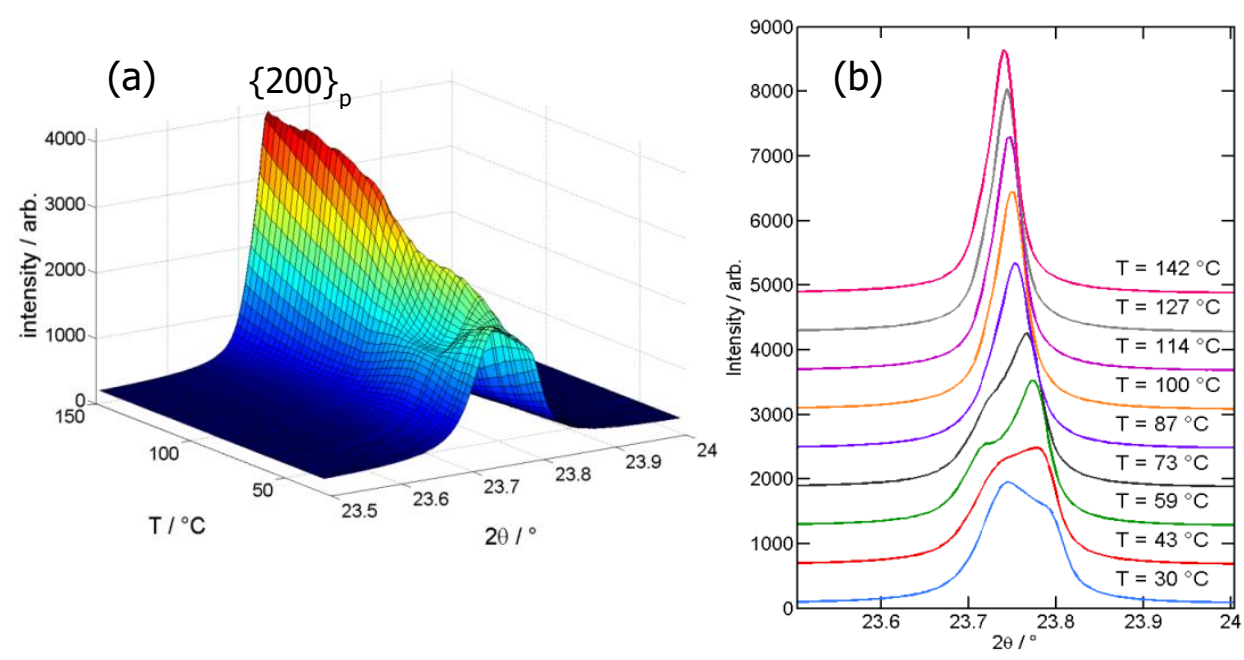

Figure 8. Changes in SXPD peak profile for $\{200\}_{p}$ reflection of BCZT-5BBS ceramic, sintered at $1200^{\circ} \mathrm{C}$. (a) 3D plot obtained during continuous heating from 30 to $140{ }^{\circ} \mathrm{C}$ and (b) $2 \mathrm{D}$ plots at selected temperatures. Variations in peak profiles are associated with thermallyinduced phase transformations.

Analysis of the temperature-dependent SXPD patterns for the BCZT-5BBS ceramic during heating from 30 to $150{ }^{\circ} \mathrm{C}$, using full-pattern refinement, is illustrated by the $\{111\}_{\mathrm{p}}$ and $\{200\}_{p}$ peak profiles presented in Figure 9. Increasing temperature caused a gradual transformation from the coexisting $\mathrm{O}$ and $\mathrm{R}$ phases at $30^{\circ} \mathrm{C}$ to a single $\mathrm{T}$ phase at $60^{\circ} \mathrm{C}$, as shown by the results presented in Table 2 . The presence of the minor rhombohedral phase at $30{ }^{\circ} \mathrm{C}$ indicates that the $\mathrm{R}-\mathrm{O}$ transformation temperature is most likely located slightly below room temperature, in accordance with the results presented by Keeble et al. [9].

It was anticipated that the $\mathrm{T}$ to $\mathrm{C}$ transformation would occur at the ferroelectric Curie temperature $\left(\approx 85^{\circ} \mathrm{C}\right)$. However, a persistent shoulder was apparent on both the $\{200\}_{\mathrm{p}}$ and $\{111\}_{\mathrm{p}}$ peak profiles at temperatures up to approximately $150{ }^{\circ} \mathrm{C}$. These results are consistent with the presence of chemical heterogeneity in the glass-modified BCZT ceramics, which takes the form of 2 distinct perovskite phases, one being the BCZT solid solution and the other comprising a BT-rich phase, as proposed in section 3.4 above. We suppose that the major BCZT phase transforms to cubic at $85^{\circ} \mathrm{C}$, while the minor BT phase retains the tetragonal structure above $85{ }^{\circ} \mathrm{C}$ and transforms to cubic around $120{ }^{\circ} \mathrm{C}$. Above this temperature, the diffraction peak profiles are broadened by the presence of two coexisting cubic phases (BCZT and BT) having slightly different lattice parameters (see Table 2). 

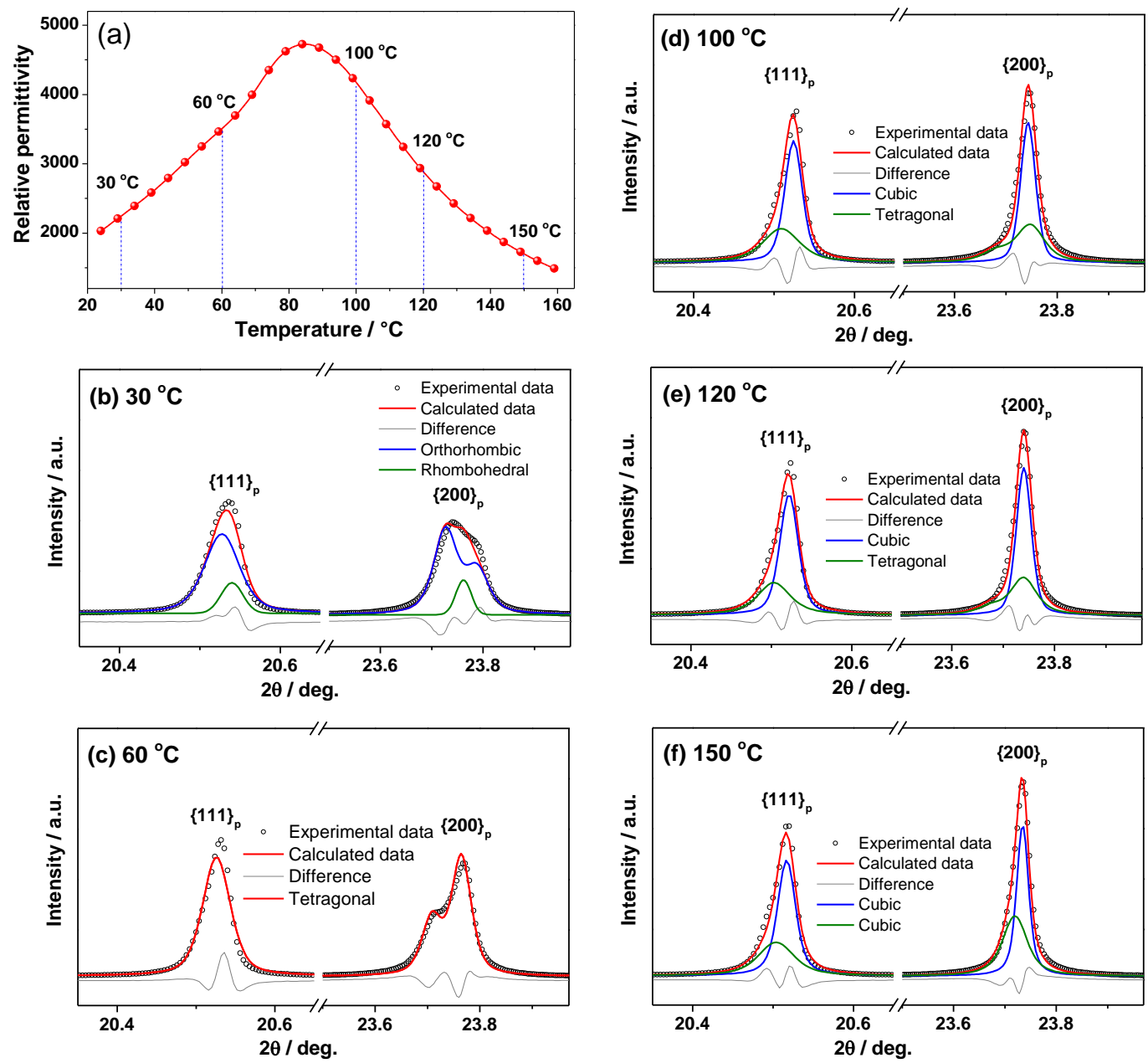

Figure 9. Full-pattern refinement of in-situ SXPD peak profiles for BCZT-5BBS during heating from 30 to $150^{\circ} \mathrm{C}$. (a) $\varepsilon_{r}-\mathrm{T}$ curve and (b)-(f) the measured, calculated and difference data obtained by full-pattern refinement showing $\{111\}_{p}$ and $\{200\}_{p}$ reflections. (b) coexisting O-R phases at $30^{\circ} \mathrm{C},(\mathrm{c})$ single $\mathrm{T}$ phase at $60^{\circ} \mathrm{C},(\mathrm{d})$-(e) coexisting C-T phases at $100-120^{\circ} \mathrm{C}$ and (f) coexisting $\mathrm{C}-\mathrm{C}$ phases (BCZT and $\mathrm{BT})$ at $150^{\circ} \mathrm{C}$.

Table 2. Coexisting phases, phase fractions, lattice parameters, $\chi^{2}$ and $R_{w p}$ obtained by full-pattern refinement for BCZT-5BBS ceramic during heating from 30 to $150^{\circ} \mathrm{C}$. Numbers in parentheses are statistical standard deviations of the last significant digit.

\begin{tabular}{|c|c|c|c|c|c|c|c|}
\hline \multirow{2}{*}{$\begin{array}{l}\text { Composition during } \\
\text { heating }\end{array}$} & \multirow{2}{*}{$\begin{array}{c}\text { Phase fraction } \\
\text { / wt } \%\end{array}$} & \multicolumn{4}{|c|}{ Lattice parameter } & \multirow{2}{*}{$x^{2}$} & \multirow{2}{*}{$\mathrm{R}_{\mathrm{wp}}$} \\
\hline & & a / $\AA$ & $\mathrm{b} / \AA$ & $c / \AA$ & $\alpha /^{\circ}$ & & \\
\hline $30^{\circ} \mathrm{C}$ & $\begin{array}{l}O=78(2) \\
R=22(1)\end{array}$ & $\begin{array}{l}a_{O}=5.6776(2) \\
a_{R}=4.0102(3)\end{array}$ & $\begin{array}{c}b_{0}=4.0059(3) \\
--\end{array}$ & $\begin{array}{c}c_{0}=5.6816(3) \\
--\end{array}$ & 89.9 & 5.71 & 4.53 \\
\hline $60^{\circ} \mathrm{C}$ & $\mathrm{T}=100$ & $\mathrm{a}_{\mathrm{T}}=4.0128(4)$ & -- & $c_{T}=4.0221(4)$ & -- & 5.98 & 4.21 \\
\hline $100^{\circ} \mathrm{C}$ & $\begin{array}{l}\mathrm{C}=59(3) \\
\mathrm{T}=41(2)\end{array}$ & $\begin{array}{l}a_{C}=4.0141(3) \\
a_{T}=4.0131(3)\end{array}$ & $\begin{array}{l}-- \\
--\end{array}$ & $c_{T}=4 . \overline{--}$ & $\begin{array}{l}-- \\
--\end{array}$ & 6.71 & 5.53 \\
\hline $120^{\circ} \mathrm{C}$ & $\begin{array}{l}C=63(2) \\
T=37(3)\end{array}$ & $\begin{array}{l}a_{C}=4.0150(1) \\
a_{T}=4.0151(3)\end{array}$ & $\begin{array}{l}-- \\
--\end{array}$ & $c_{T}=4 . \overline{0258(4)}$ & $\begin{array}{l}-- \\
--\end{array}$ & 7.21 & 6.57 \\
\hline $150^{\circ} \mathrm{C}$ & $\begin{array}{l}C=73(2) \\
C=27(1)\end{array}$ & $\begin{array}{l}a_{c}=4.0158(2) \\
a_{C}=4.0183(3)\end{array}$ & $\begin{array}{l}-- \\
--\end{array}$ & $\begin{array}{l}-- \\
--\end{array}$ & $\begin{array}{l}-- \\
--\end{array}$ & 6.82 & 6.13 \\
\hline
\end{tabular}




\subsection{Ferroelectric properties}

The P-E hysteresis loops obtained for pure BCZT and BCZT-BBS ceramics at room temperature are presented in Figure 10. In the case of pure BCZT, Figure 10 (a), a sintering temperature of $1400{ }^{\circ} \mathrm{C}$ yielded a well-defined ferroelectric loop having saturation polarisation, $P_{s}$, remanent polarisation, $P_{r}$, and coercive field, $E_{c}$, values of $0.19 \mathrm{C} \mathrm{m}^{-2}$, $0.09 \mathrm{C} \mathrm{m}^{-2}$ and $0.30 \mathrm{kV} \mathrm{mm}^{-1}$ respectively. In contrast, the P-E loops of the pure BCZT ceramics sintered at 1300 and $1350{ }^{\circ} \mathrm{C}$ were poorly saturated and exhibited a 'rounded' appearance, indicating high losses. Loops of this form are commonly observed in specimens having high porosity and therefore can be attributed to the poor densification achieved in pure BCZT at sintering temperatures lower than $1400{ }^{\circ} \mathrm{C}$. The low polarisation values result from high porosity, poor crystallinity and very fine grain size, while the 'rounding' effect is caused by conduction currents associated with poor insulation resistance.

The influence of sintering temperature on the ferroelectric behaviour of BCZT-5BBS ceramics is illustrated by the results presented in Figure 10 (b). In this case, well-formed P-E loops with relatively high $\mathrm{P}$ values were obtained for sintering temperatures of 1200 and $1300{ }^{\circ} \mathrm{C}$, while that of the ceramic sintered at $1100{ }^{\circ} \mathrm{C}$ yielded low $\mathrm{P}$ values as a result of its lower density. The $\mathrm{P}$ values were reduced somewhat relative to the pure BCZT ceramic, due to the presence of the low-permittivity glass phase between the ferroelectric BCZT grains. For example, the BCZT-5BBS ceramic sintered at $1300{ }^{\circ} \mathrm{C}$ yielded $\mathrm{P}_{\mathrm{s}}$ and $\mathrm{P}_{\mathrm{r}}$ values of 0.123 and $0.054 \mathrm{C} \mathrm{m}^{-2}$ respectively, which were approximately $32 \%$ lower than those of the pure BCZT ceramic sintered at $1400{ }^{\circ} \mathrm{C}$. On the other hand, the BCZT-5BBS ceramic sintered at $1200{ }^{\circ} \mathrm{C}$ yielded a slightly higher $\mathrm{P}_{\mathrm{s}}$ value of $0.14 \mathrm{C} \mathrm{m}^{-2}$ but a lower $\mathrm{P}_{\mathrm{r}}$ value of $0.040 \mathrm{C} \mathrm{m}^{-2}$. The observed variations in ferroelectric switching behaviour with sintering temperature can be correlated with the $\varepsilon_{r}-T$ relationships shown in Figure 7 (a), where it is apparent that the BCZT-5BBS ceramic sintered at the highest temperature of $1300{ }^{\circ} \mathrm{C}$ exhibited a more welldefined Curie point but the relative permittivity at room temperature was slightly higher for the ceramic sintered at $1200^{\circ} \mathrm{C}$. 

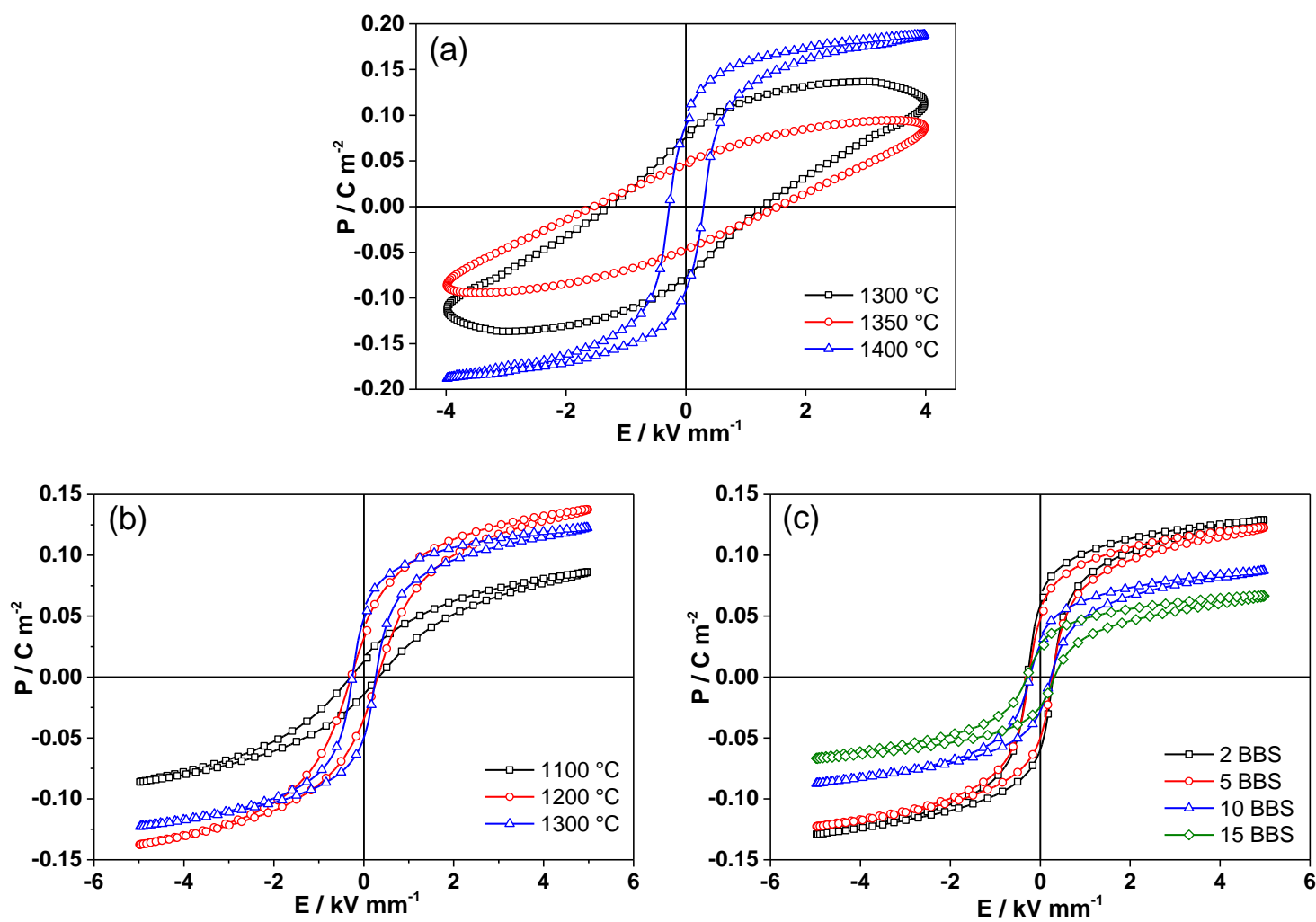

Figure 10. P-E hysteresis loops obtained for (a) pure BCZT sintered at $1300^{\circ} \mathrm{C}$ to $1400^{\circ} \mathrm{C}$, (b) BCZT5BBS sintered at $1100^{\circ} \mathrm{C}$ to $1300^{\circ} \mathrm{C}$ and (c) BCZT-BBS sintered at $1300^{\circ} \mathrm{C}$.

For a given sintering temperature of $1200{ }^{\circ} \mathrm{C}$, increasing BBS content had little influence on $\mathrm{P}_{\mathrm{r}}$ and $\mathrm{E}_{\mathrm{c}}$, but led to significant reductions in $\mathrm{P}_{\mathrm{s}_{1}}$ as shown in Figure 10 (c). The resulting variations in $\mathrm{P}_{\mathrm{s}}$ and $\mathrm{P}_{\mathrm{r}}$ as a function of BBS content and sintering temperature are illustrated in Figure 11. The highest $\mathrm{P}_{\mathrm{s}}$ values were consistently obtained for the BCZT-BBS ceramics sintered at $1200{ }^{\circ} \mathrm{C}$, while the higher sintering temperature of $1300^{\circ} \mathrm{C}$ yielded the highest $\mathrm{Pr}$ values. Further work is required to optimise the ferroelectric switching behaviour of these materials, and hence to obtain improved remanent polarisation values. This could include investigations into the properties of BCZT-BBS ceramics sintered at intermediate temperatures in the range 1200 to $1300{ }^{\circ} \mathrm{C}$, for example. 

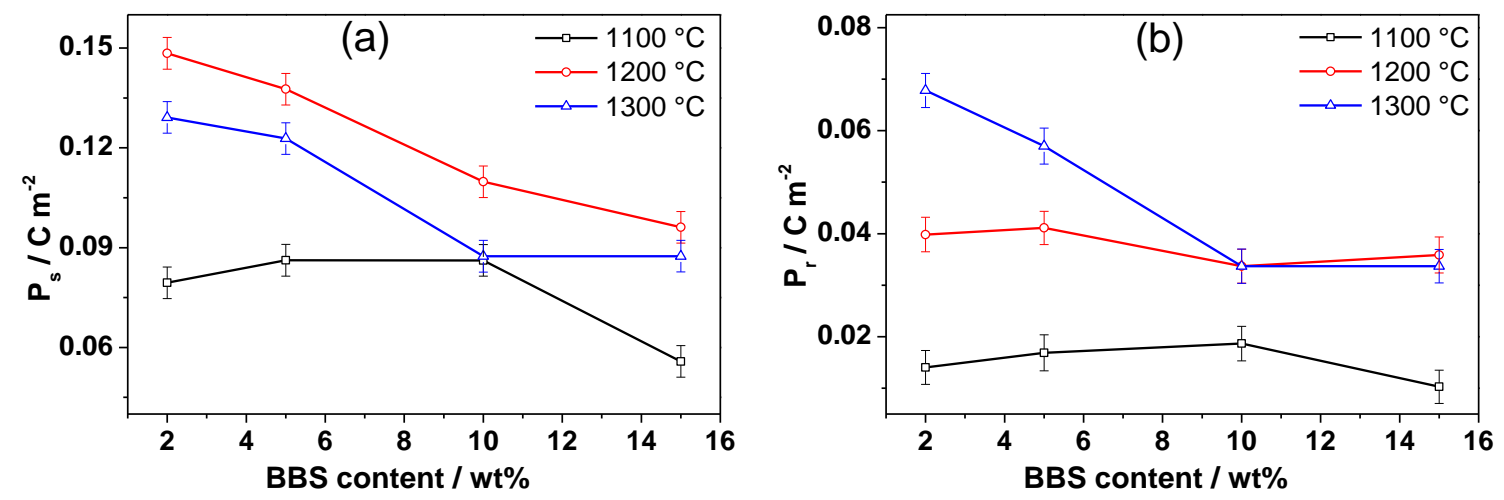

Figure 11. Influence of BBS content on (a) $\mathrm{P}_{s}$ and (b) $\mathrm{Pr}$ of BCZT-BBS ceramics sintered at temperatures from 1100 to $1300^{\circ} \mathrm{C}$.

The influence of temperature on ferroelectric properties was evaluated by recording the P-E hysteresis loops of pure and glass-modified BCZT ceramics over a range of temperatures from 25 to $140{ }^{\circ} \mathrm{C}$, as illustrated by the results presented in Figure 12. The P-E loops generally decreased in height with increasing temperature but did not collapse fully into linear loss-free behaviour at temperatures up to $140{ }^{\circ} \mathrm{C}$. The $\mathrm{P}_{\mathrm{s}}$ values reduced gradually over the full temperature range, while $\operatorname{Pr}$ dropped relatively sharply between 80 and $100{ }^{\circ} \mathrm{C}$ due to the ferroelectric phase transformation. The coercive field values varied little over this temperature range. Significant nonlinearity and finite $\operatorname{Pr}$ values above $100{ }^{\circ} \mathrm{C}$ could be caused by electric field-induced paraelectric-ferroelectric phase transformations in the region of $\mathrm{T}_{\mathrm{C}}$.

The temperature-dependent polarisation values obtained for BCZT ceramics with different glass contents are summarised in Figure 12 (c)-(d). The relatively rapid loss of remanent polarisation above $80^{\circ} \mathrm{C}$ is clearly apparent in these results. However, it is also clear that significantly nonlinearity and saturation in dielectric properties occurs even above the Curie point. For example, the saturation polarisation, $\mathrm{P}_{\mathrm{S}}$, for BCZT-5BBS at $140{ }^{\circ} \mathrm{C}$ was measured as $0.061 \mathrm{C} \mathrm{m}^{-2}$ at an electric field of $5 \mathrm{kV} \mathrm{mm}^{-1}$. This is somewhat lower than the predicted value of $0.088 \mathrm{C} \mathrm{m}^{-2}$, calculated by assuming a linear dielectric response with a permittivity of 2000 at an electric field of $5 \mathrm{kV} \mathrm{mm}^{-1}$. 

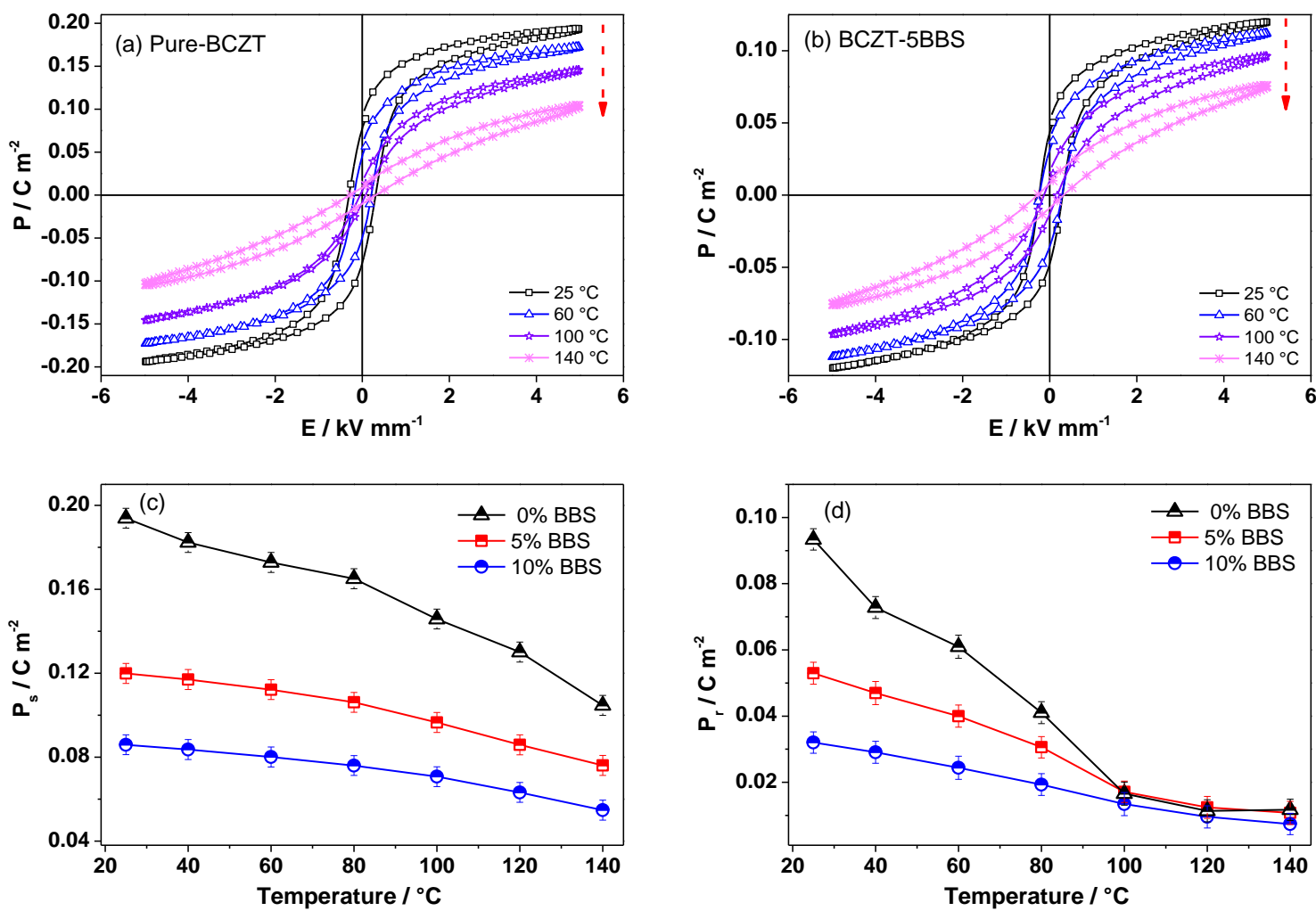

Figure 12. Influence of temperature on P-E hysteresis loops of (a) pure BCZT $\left(1400^{\circ} \mathrm{C}\right)$ and $(b)$ BCZT-5BBS $\left(1300^{\circ} \mathrm{C}\right)$. Variations in (c) Ps and (d) Pr of pure BCZT and BCZT-BBS as a function of temperature. Arrows in (a) and (b) indicate increasing temperature.

The influence of BBS glass on the longitudinal strain-electric field response at room temperature is illustrated by the results presented in Figure 13 (a). The dramatic reductions in strain with increasing glass content are consistent with the P-E measurements reported above and are attributed to the electric field screening effect caused by the low-permittivity BBS glass phase between the BCZT grains. By utilising the simultaneous measurements of the strain and polarisation components, $\mathrm{x}_{33}$ and $\mathrm{P}_{3}$ respectively, it is also possible to evaluate the influence of glass content on electrostrictive behaviour. The method used here follows a similar approach to that described by Weaver et al., who examined the electrostrictive responses of a soft PZT ceramic as a function of temperature [33].

In the present case, the strain and polarisation data obtained on decreasing the electric field in the partly-saturated region, between 4 and $1 \mathrm{kV} \mathrm{mm}^{-1}$, were re-plotted to illustrate the linear electrostrictive $\mathrm{x}_{33}-\mathrm{P}_{3}{ }^{2}$ relationships, as shown in Figure 13 (b). These results were then employed to calculate the longitudinal electrostrictive coefficient, $Q_{3333}$, by a linear least-squares fitting procedure, according to the definition given in equation 2 .

$$
\mathrm{X}_{33}=\mathrm{Q}_{3333} \mathrm{P}_{3}^{2}
$$


Somewhat surprisingly, it was found that the values of the electrostrictive coefficient were affected strongly by the BBS glass content. For example, the pure BCZT and BCZT-2BBS ceramics yielded $\mathrm{Q}_{3333}$ values of approximately 0.025 and $0.054 \mathrm{C}^{-2} \mathrm{~m}^{4}$ respectively. The value of $\mathrm{Q}_{3333}$ continued to increase systematically with further increases in glass content, reaching a value of $0.084 \mathrm{C}^{-2} \mathrm{~m}^{4}$ for the BCZT-15BBS ceramic. The origin of these variations in $\mathrm{Q}_{3333}$ with glass content is not immediately obvious, but it could be associated with changes in phase composition (as listed in

Table 1) or alternatively with changes in the polarisation mechanisms associated with particle crystallinity and grain size variations. Irrespective of its origin, this could be an important factor to consider for the applications of such materials in dielectric energy storage devices, where a high electrostrictive coefficient could potentially create undesirable mechanical stresses at high electric field/polarisation levels.
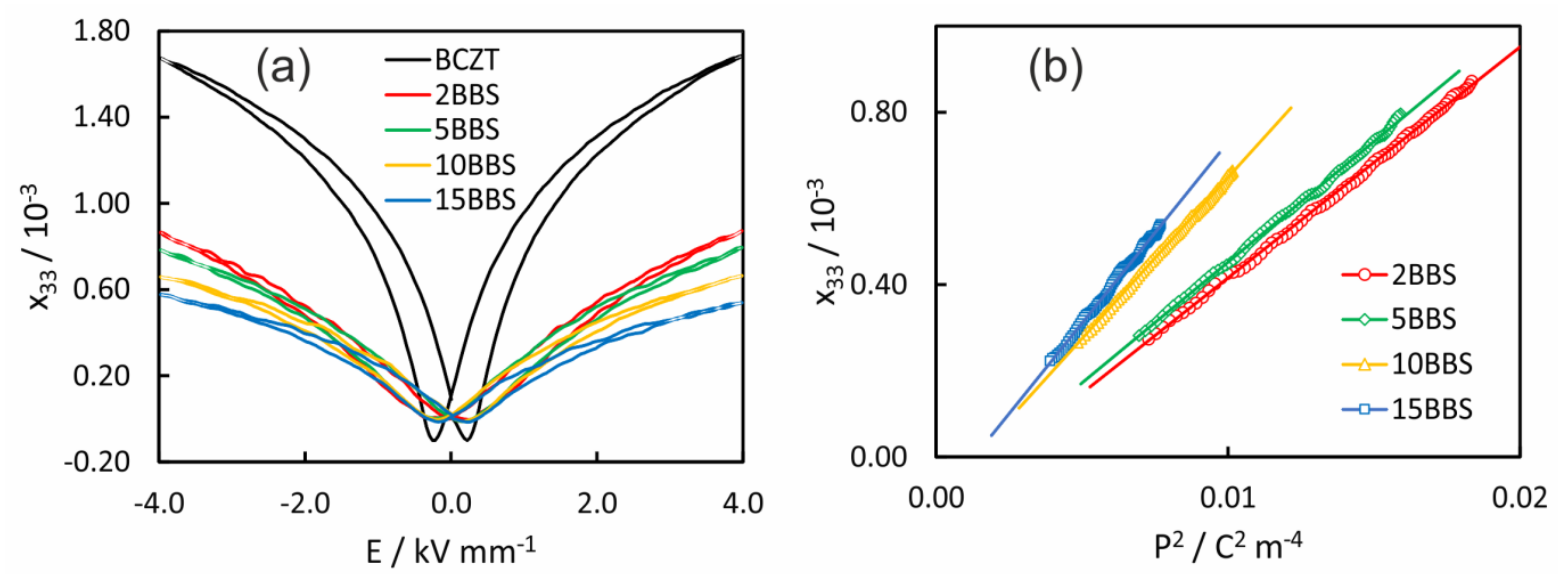

Figure 13. Influence of BBS on (a) strain-electric field loops and (b) strain- $\mathrm{P}^{2}$ relationships. The latter are plotted to enable determination of the longitudinal electrostrictive coefficient; results for pure BCZT are omitted for clarity.

The P-E loops and recoverable (stored) energy density, $U_{\text {rec, }}$ values, calculated from the area between the P-E curve and the polarisation axis for the pure and glass-modified BCZT ceramics, are shown in Figure 14. It is evident that the addition of the BBS glass led to a significant reduction in $\mathrm{P}_{\mathrm{S}}$ (from 0.187 to $0.102 \mathrm{C} \mathrm{m}^{-2}$ ), but the $\mathrm{U}_{\text {rec }}$ values for pure BCZT and the BCZT-2BBS ceramics are similar. This effect is attributed to the concomitant reduction in $\operatorname{Pr}$ (from 0.096 to $0.035 \mathrm{C} \mathrm{m}^{-2}$ ). Both the pure and glass-modified BCZT ceramics showed a tendency for saturation in the P-E loops, giving rise to sub-linear $U_{\text {rec }}-E_{\max }$ relationships, but the incorporation of BBS glass could potentially yield a higher breakdown field strength and hence enable the use of higher $E_{\max }$ values in order to enhance $U_{\text {rec. }}$. 

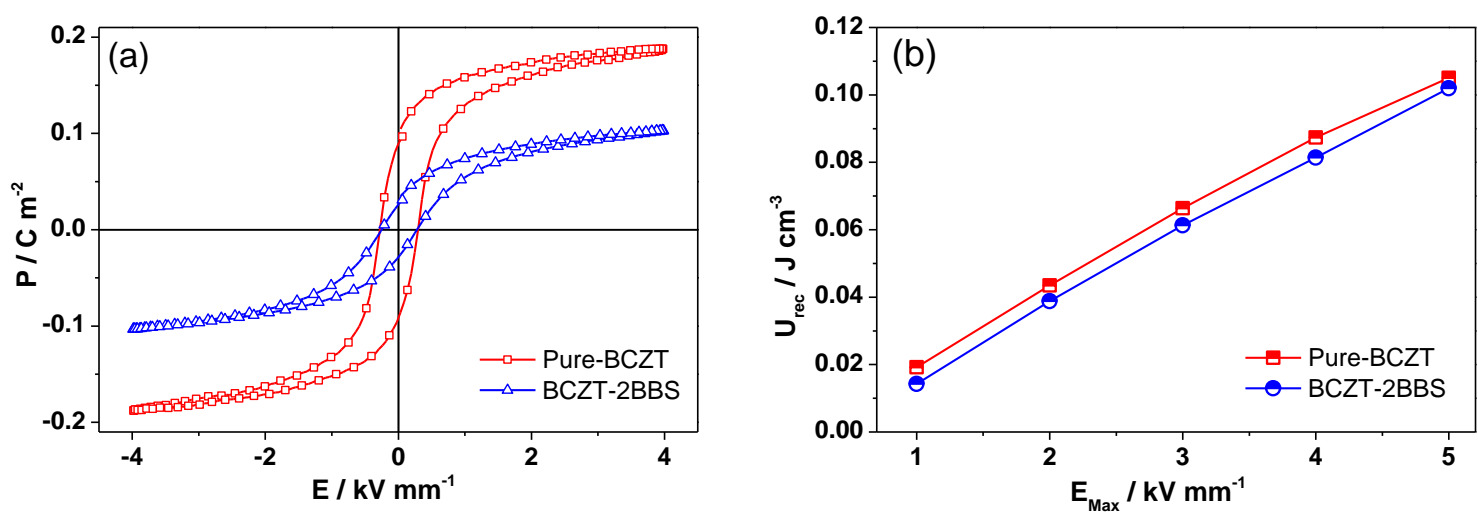

Figure 14 (a) P-E hysteresis loops obtained for pure BCZT and BCZT-2BBS and (b) the recoverable (stored) energy density of pure BCZT and BCZT-2BBS, sintered at temperatures of 1400 and $1200^{\circ} \mathrm{C}$ respectively, as a function of the maximum electric field.

\section{Conclusions}

BBS glass was shown to be an effective sintering aid for BCZT ceramics, enhancing densification at relatively low processing temperatures $\left(\approx 1200{ }^{\circ} \mathrm{C}\right)$. The presence of the low permittivity glass phase between the ferroelectric BCZT grains led to significant reductions in relative permittivity and electric field-induced polarisation, these effects becoming more pronounced with increasing glass content. Additional inflections were observed in the dielectric permittivity-temperature curves of the glass-modified BCZT ceramics, indicating the occurrence of further phase transformations that were not apparent in the unmodified material.

Structural studies using SXPD suggested that the unmodified and glass-modified BCZT ceramics were predominantly tetragonal with minor orthorhombic phase and orthorhombic with minor rhombohedral phase respectively. These changes in phase composition are explained on the basis that the incorporation of the BBS glass caused an increase in $\mathrm{T}_{\mathrm{O}-\mathrm{T}}$, from below room temperature to $\approx 50{ }^{\circ} \mathrm{C}$. Furthermore, the diffraction peaks retained a pronounced asymmetry at high temperatures extending into the paraelectric cubic region, indicating the presence of chemical heterogeneity within the crystalline perovskite phases. It is proposed that the heterogeneity is a result of redistribution of the dopants by dissolution and reprecipitation mechanisms through the liquid phase during sintering. 


\section{Acknowledgments}

We thank Diamond Light Source for the access to beamline I11 (proposal number EE 14106) that contributed to the results presented here. The assistance of Dr. Sarah Day and Prof. Chiu Tang is gratefully acknowledged. We also thank Dr Antonio Feteira (Sheffield Hallam University) and Mr Mohammed Al-Aaraji (University of Manchester) for their assistance with the electric field-induced strain measurements.

Abdulkarim Khalf would like to thank the Ministry of Higher Education and Scientific Research represented by the Iraqi Cultural Attaché in London, and the University of Technology, Baghdad, Iraq for financial support in the form of a PhD scholarship at the University of Manchester. 


\section{References}

[1] A.J. Moulson, J.M. Herbert, Electroceramics, John Wiley \& Sons Ltd, 2003.

[2] P. K. Panda, B. Sahoo, PZT to Lead Free Piezo Ceramics: A Review, Ferroelectrics 474(1) (2015) 128-143.

[3] H. Wang, J. Wu, Phase transition, microstructure, and electrical properties of $\mathrm{Ca}$, $\mathrm{Zr}$, and $\mathrm{Sn}$ modified $\mathrm{BaTiO}_{3}$ lead-free ceramics, Journal of Alloys and Compounds 615 (2014) 969-974.

[4] Y. Bai, A. Matousek, P. Tofel, V. Bijalwan, B. Nan, H. Hughes, T.W. Button, (Ba,Ca)(Zr,Ti)O 3 leadfree piezoelectric ceramics-The critical role of processing on properties, Journal of the European Ceramic Society 35(13) (2015) 3445-3456.

[5] M.C. Ehmke, F.H. Schader, K.G. Webber, J. Rödel, J.E. Blendell, K.J. Bowman, Stress, temperature and electric field effects in the lead-free $(\mathrm{Ba}, \mathrm{Ca})(\mathrm{Ti}, \mathrm{Zr}) \mathrm{O} 3$ piezoelectric system, Acta Materialia 78 (2014) 37-45.

[6] M. Acosta, N. Novak, W. Jo, J. Rödel, Relationship between electromechanical properties and phase diagram in the $\mathrm{Ba}(\mathrm{Zr} 0.2 \mathrm{Ti} 0.8) \mathrm{O} 3-\mathrm{x}(\mathrm{Ba} 0.7 \mathrm{Ca} 0.3$ )TiO 3 lead-free piezoceramic, Acta Materialia 80 (2014) 48-55.

[7] W. Bai, D. Chen, P. Li, B. Shen, J. Zhai, Z. Ji, Enhanced electromechanical properties in <00l>textured (Ba $0.85 \mathrm{Ca} 0.15$ )( $\mathrm{Zr} 0.1 \mathrm{Ti} 0.9$ ) 3 lead-free piezoceramics, Ceramics International $42(2)$ (2016) 3429-3436.

[8] W. Liu, X. Ren, Large piezoelectric effect in Pb-free ceramics, Phys Rev Lett. 103(25) (2009) 1-4.

[9] D.S. Keeble, F. Benabdallah, P.A. Thomas, M. Maglione, J. Kreisel, Revised structural phase diagram of ( $\left.\mathrm{Ba}_{0.7} \mathrm{Ca}_{0.3} \mathrm{TiO}_{3}\right)-\left(\mathrm{BaZr}_{0.2} \mathrm{Ti}_{0.8} \mathrm{O}_{3}\right)$, Applied Physics Letters 102(9) (2013) 1-5.

[10] Y. Tian, Y. Gong, D. Meng, S. Cao, Structure and electrical properties of $\mathrm{Ir}^{4+}$-doped $0.5 \mathrm{Ba}_{0.9} \mathrm{Ca}_{0.1} \mathrm{TiO}_{3}-0.5 \mathrm{BaTi}_{0.88} \mathrm{Zr}_{0.12} \mathrm{O}_{3}-0.12 \%$ La ceramics via a modified Pechini method, Materials Letters 153 (2015) 44-46.

[11] H. Kaddoussi, A. Lahmar, Y. Gagou, B. Manoun, J.N. Chotard, J.L. Dellis, Z. Kutnjak, H. Khemakhem, B. Elouadi, M. El Marssi, Sequence of structural transitions and electrocaloric properties in $\left(\mathrm{Ba}_{1-\mathrm{x}} \mathrm{Ca}_{\mathrm{x}}\right)\left(\mathrm{Zr}_{0.1} \mathrm{Ti}_{0.9}\right) \mathrm{O}_{3}$ ceramics, Journal of Alloys and Compounds 713 (2017) 164179.

[12] S.-H. Shin, J.-D. Han, J. Yoo, Piezoelectric and dielectric properties of $\mathrm{B}_{2} \mathrm{O}_{3}$-added $\left(\mathrm{Ba}_{0.85} \mathrm{Ca}_{0.15}\right)\left(\mathrm{Ti}_{0.915} \mathrm{Zr}_{0.085}\right) \mathrm{O}_{3}$ ceramics sintered at low temperature, Materials Letters 154 (2015) 120-123.

[13] X. Chao, J. Wang, L. Wei, R. Gou, Z. Yang, Electrical properties and low temperature sintering of $\mathrm{BiAlO}_{3}$ doped $\left(\mathrm{Ba}_{0.85} \mathrm{Ca}_{0.15}\right)\left(\mathrm{Zr}_{0.1} \mathrm{Ti}_{0.9}\right) \mathrm{O}_{3}$ lead-free piezoelectric ceramics, Journal of Materials Science: Materials in Electronics 26(10) (2015) 7331-7340.

[14] T. Chen, T. Zhang, G. Wang, J. Zhou, J. Zhang, Y. Liu, Effect of CuO on the microstructure and electrical properties of $\mathrm{Ba}_{0.85} \mathrm{Ca}_{0.15} \mathrm{Ti}_{0.90} \mathrm{Zr}_{0.10} \mathrm{O}_{3}$ piezoceramics, Journal of Materials Science $47(11)$ (2012) 4612-4619.

[15] P. Parjansri, K. Pengpat, G. Rujijanagul, T. Tunkasiri, U. Intatha, S. Eitssayeam, Effect of $\mathrm{Zn}^{2+}$ and $\mathrm{Nb}^{5+}$ Co-Doping on Electrical Properties of BCZT Ceramics by the Seed-Induced Method, Ferroelectrics 458(1) (2014) 91-97.

[16] W. Bai, B. Shen, F. Fu, J. Zhai, Dielectric, ferroelectric, and piezoelectric properties of textured BZT-BCT lead-free thick film by screen printing, Materials Letters 83 (2012) 20-22.

[17] V.S. Puli, D.K. Pradhan, A. Kumar, R.S. Katiyar, X. Su, C.M. Busta, M. Tomozawa, D.B. Chrisey, Structure and dielectric properties of $\mathrm{BaO}-\mathrm{B}_{2} \mathrm{O}_{3}-\mathrm{ZnO}-\left[\left(\mathrm{BaZr}_{0.2} \mathrm{Ti}_{0.8}\right) \mathrm{O}_{3}\right]_{0.85}-\left[\left(\mathrm{Ba}_{0.7} \mathrm{Ca}_{0.3}\right) \mathrm{TiO}_{3}\right]_{0.15}$ glass-ceramics for energy storage, Journal of Materials Science: Materials in Electronics 23(11) (2012) 2005-2009. 
[18] Y. Lai, Y. Zeng, X. Tang, H. Zhang, J. Han, Z. Huang, H. Su, Effects of $\mathrm{CaO}-\mathrm{B}_{2} \mathrm{O}_{3}-\mathrm{SiO}_{2}$ glass additive on the microstructure and electrical properties of BCZT lead-free ceramic, Ceramics International 42(11) (2016) 12694-12700.

[19] H. Sun, Y. Zhang, X. Liu, Y. Liu, S. Guo, W. Chen, Effects of cobalt and sintering temperature on electrical properties of $\mathrm{Ba}_{0.98} \mathrm{Ca}_{0.02} \mathrm{Zr}_{0.02} \mathrm{Ti}_{0.98} \mathrm{O}_{3}$ lead-free ceramics, Journal of Materials Science: Materials in Electronics 25(9) (2014) 3962-3966.

[20] A. Shukla, Development of a critically evaluated thermodynamic database for the systems contaning alkaline-earth oxides, University of Montreal, PhD, 2012.

[21] E.-S. Lim, B.-S. Kim, J.-H. Lee, J.-J. Kim, Characterization of the low temperature firing $\mathrm{BaO}-$ $\mathrm{B}_{2} \mathrm{O}_{3}-\mathrm{SiO}_{2}$ glass: The effect of $\mathrm{BaO}$ content, Journal of the European Ceramic Society $27(2-3)$ (2007) 825-829.

[22] X.-m. Cui, Y. He, Z.-y. Liang, H. Zhang, J. Zhou, Different microstructure $\mathrm{BaO}-\mathrm{B}_{2} \mathrm{O}_{3}-\mathrm{SiO}_{2}$ glass/ceramic composites depending on high-temperature wetting affinity, Ceramics International 36(4) (2010) 1473-1478.

[23] Bruker AXS GmbH-Germany, Diffrac Suite, User Manual, TOPAS v.5 Tutorial, (2014).

[24] L. B. McCusker, R. B. Von Dreele, D. E. Cox, D. LoueÈrd, P. Scardie, Rietveld refinement guidelines, J. Appl. Cryst 32 (1999) 36-50.

[25] H. Abrams, Grain Size Measurement by the Intercept Method, Metallography 4 (1971) 59-78.

[26] M. Stewart, M. G. Cain, D.A. Hall, Ferroelectric Hysteresis, Measurement \& Analysis., NPL Report CMMT(A) 152 (1999) 1-51.

[27] J. Hao, W. Bai, W. Li, J. Zhai, C. Randall, Correlation Between the Microstructure and Electrical Properties in High-Performance (Ba0.85Ca0.15)( $\left.\mathrm{Zr}_{0.1 \mathrm{Ti}} \mathrm{Ti}_{9}\right) \mathrm{O}_{3}$ Lead-Free Piezoelectric Ceramics, Journal of the American Ceramic Society 95(6) (2012) 1998-2006.

[28] N. Pisitpipathsin, K. Puripat, P. Kamonpan, R. Gobwute, Influence of Ca substitution on microstructure and electrical properties of $\mathrm{Ba}(\mathrm{Zr}, \mathrm{Ti}) \mathrm{O}_{3}$ ceramics, Ceramics International 39 (2013) S35-S39.

[29] Hui-Fen Wu, Chung-Cherng Lin, P. Shen, Structure and dissolution of $\mathrm{CaO}-\mathrm{ZrO}_{2}-\mathrm{TiO}_{2}-\mathrm{Al}_{2} \mathrm{O}_{3}-$ $\mathrm{B}_{2} \mathrm{O}_{3}-\mathrm{SiO}_{2}$ glass (II), Journal of Non-Crystalline Solids 209 (1997) 76-86.

[30] V. Rajendran, A. V. Gayathri Devi, M. Azooz, F.H. El-Batal, Physicochemical studies of phosphate based $\mathrm{P}_{2} \mathrm{O}_{5}-\mathrm{Na}_{2} \mathrm{O}-\mathrm{CaO}-\mathrm{TiO}_{2}$ glasses for biomedical applications, Journal of Non-Crystalline Solids 353(1) (2007) 77-84.

[31] T. Lee, C. Huang, C. Chang, S. Lin, C. Su, C. Lee, M. Fujimoto, Phase Evolution and Nucleus Growth Observation of Solid-State $\mathrm{BaTiO}_{3}$ Powder Prepared by High-Energy Bead Milling for Raw Material Mixing, Japanese Journal of Applied Physics 50 (2011) 091502(1-6).

[32] J. Ravez, C. Broustera, A. Simon, Lead-free ferroelectric relaxor ceramics in the BT-BZ-CT system, J. Mater. Chem. 9 (1999) 1609-1613.

[33] P.M. Weaver, M.G. Cain, M. Stewart, Temperature dependence of high field electromechanical coupling in ferroelectric ceramics, Journal of Physics D: Applied Physics 43(16) (2010) 165404 (17). 